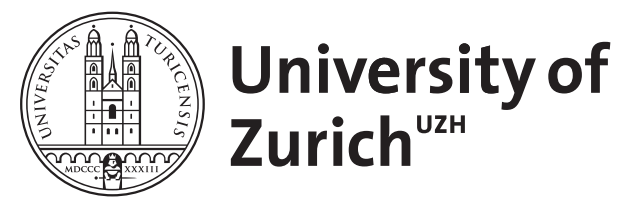

\title{
Spinal neuroplasticity in chronic pain
}

\author{
Zeilhofer, Hanns Ulrich
}

\begin{abstract}
Neuroplastic changes play an important role in the generation and maintenance of chronic pain syndromes. Such changes occur at all levels of the neuraxis, from the peripheral terminals of primary sensory neurons to the cerebral cortex. Changes observed in the spinal dorsal horn in particular provide a mechanistic basis for many of the characteristics of chronic pain syndromes. While facilitated synaptic transmission between nociceptive fibers and spinal projection neurons contributes to enhanced perception of noxious stimuli (hyperalgesia), diminished function of GABAergic and glycinergic interneurons not only induces hyperalgesia, but also triggers nociceptive reactions on exposure to innocuous stimuli and spontaneous pain behavior in the absence of any sensory stimulation. Spinal disinhibition thus recapitulates typical symptoms of chronic pathological pain syndromes. Studies performed by various groups over the last 10 years demonstrate that such spinal disinhibition occurs naturally in response to peripheral inflammation and nerve damage. The present article summarizes current status of this research.
\end{abstract}

DOI: https://doi.org/10.1007/s13295-011-0018-1

Posted at the Zurich Open Repository and Archive, University of Zurich

ZORA URL: https://doi.org/10.5167/uzh-59190

Journal Article

Published Version

Originally published at:

Zeilhofer, Hanns Ulrich (2011). Spinal neuroplasticity in chronic pain. e-Neuroforum, 2(2):35-41.

DOI: https://doi.org/10.1007/s13295-011-0018-1 
e-Neuroforum $2011 \cdot 2: 35-41$

DOI 10.1007/s13295-011-0018-1

(c) Springer-Verlag 2011

\section{H.U. Zeilhofer}

Institut für Pharmakologie und Toxikologie, Universität Zürich, Zürich

\section{Spinal neuroplasticity in chronic pain}

\section{Introduction}

Our body detects potentially noxious stimuli by means of nociceptors, specialized neurons which translate physical or chemical stimuli into electrical signals and transmit these to the central nervous system (CNS). The majority of these (primary) nociceptors are non-myelinated slowly conducting $\mathrm{C}$ fibers or thinly myelinated fast conducting $A \delta$ fibers, the central endings of which end either in the dorsal horn of the spinal cord or in the trigeminal nucleus of the brainstem. The initial synaptic integration of nociceptive information occurs in these structures. Some of the spinal terminals of nociceptors directly stimulate projection neurons in the most dorsal layer of the spinal cord, the lamina I, while other nociceptor endings activate excitatory or inhibitory local interneurons in the same lamina as well as the underlying lamina II. Non-nociceptive mechanosensitive fibers that are activated by mild tactile stimuli end primarily in deep layers of the dorsal horn, where they come in contact with a different class of projection neurons, as well as with excitatory and inhibitory interneurons. In this way, the neuronal network of the dorsal horn integrates peripheral nociceptive and nonnociceptive stimuli with pro- and antinociceptive signals from pathways descending from the brainstem and midbrain into the spinal cord. The result of this spinal processing is then transmitted via several interconnections by lamina-I projection neurons in lamina I to higher CNS areas, where nociceptive and non-nociceptive stimuli are consciously perceived. Neuroplastic changes in this network represent an important mechanism of chronic pain.

\section{Synaptic plasticity in lamina-I projection neurons}

Lamina-I projection neurons in the dorsal horn play a crucial role in the perception of chronic inflammatory and neuropathic pain. The majority of these projection neurons are nocispecific neurons which, under physiological conditions, are activated exclusively by noxious stimuli. They carry neurokinin 1 (NK1) receptors for the neuropeptide substance $\mathrm{P}$ released from peptidergic $C$ fibers. This latter characteristic has been used to destroy these spinal neurons in a targeted manner. Animals in which a conjugate comprising

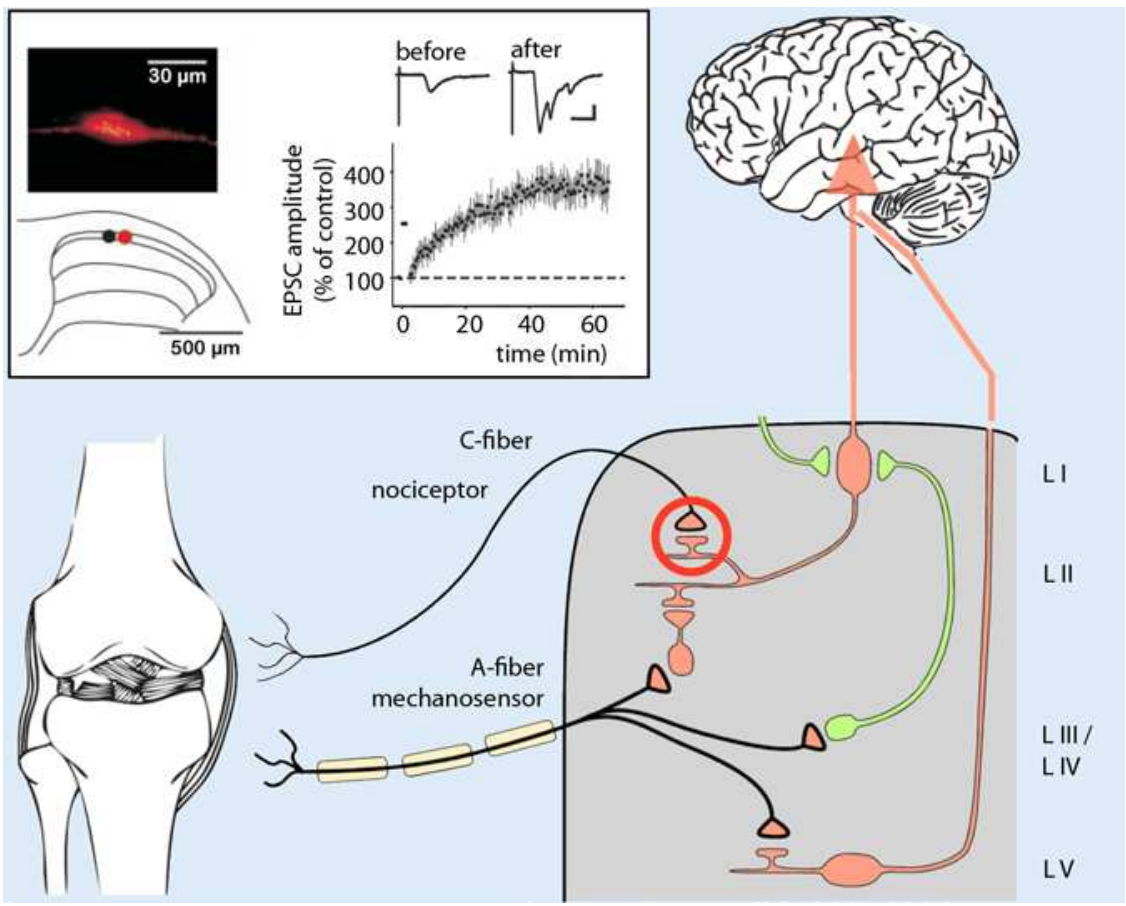

Fig. $1 \Delta$ Long-term potentiation at the synapse between primary nociceptors and nocispecific projection neurons in the lamina I. Intense stimulation of nociceptor endings leads to a persistent increase in synaptic transmission onto the projection neuron, as well as to hyperalgesia at the site of nociceptor stimulation. $L I-L V$ indicate the various spinal laminae according to Rexed. (Modified from [13]) substance $\mathrm{P}$ and saporin was injected in the spinal cord were almost completely protected against inflammatory and neuropathic hyperalgesia [24]. Pursuing this idea, the plasticity of the synapses between primary nociceptors and these projection neurons have been closely investigated in recent years [13]. It could be demonstrated that intensive stimulation of these synapses triggers long-term potentiation (LTP). In particular, synapses with neurons that project to the periaqueductal gray (PAG), undergo LTP already with stimulation frequencies mimicking natural $\mathrm{C}$ fiber activity (• Fig. 1). 
a
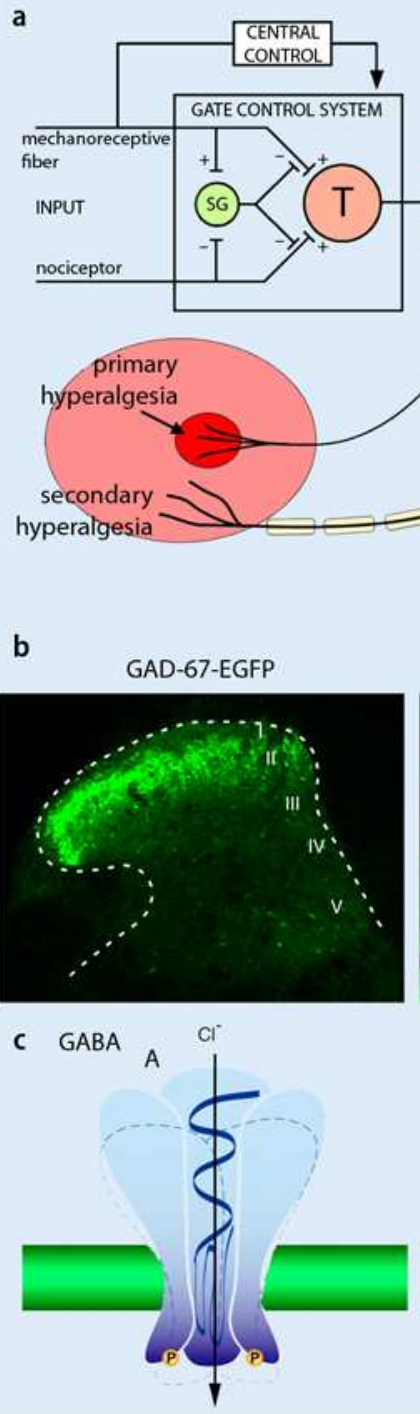

Fig. $2 \Delta$ a Primary and secondary hyperalgesia. In addition to sensitization at the site of nociceptor stimulation (primary hyperalgesia, dark red area), hypersensitivity to signals from non-nociceptive fibers also occurs in neighboring unconditioned areas (secondary hyperalgesia, light red area). Under physiological conditions, nociceptor signals are transmitted via nocispecific neurons $(\mathrm{N})$ to supraspinal centers, while non-nociceptive signals are transmitted via wide dynamic range neurons in the deep dorsal horn. Left"Gate control" theory of pain (modified according to [18]). Inhibitory interneurons in the superficial dorsal horn, the substantia gelatinosa (SG), determine whether signals are transmitted through the spinal transmission system $(T)$ to the brain. The activity of these inhibitory interneurons is inversely regulated by nociceptors and non-nociceptive fibers. b GABAergic and glycinergic interneurons, visualized here by cell type-specific expression of enhanced green fluorescent protein $(E G F P)$, are abundant in the superficial dorsal horn. $c$ Both transmitters open chloride channels $\left(G A B A_{A}\right.$ and strychnine-sensitive glycine receptors), which inhibit the activation of postsynaptic neurons

\section{Inhibitory interneurons in spinal control of nociception}

Although homosynaptic plasticity at C-fiber synapses is able to explain increased pain perception at the site of nociceptor stimulation (i.e., primary hyperalgesia), it is not able to simply explain why sensitization to signals from unconditioned inputs also occurs. Indeed, local C-fiber stimu- lation-experimentally inducible by, e.g., injection of capsaicin, a selective activator of nociceptors-also leads to hypersensitivity in unconditioned neighboring tissue and to pain originating from stimulation of non-nociceptive (capsaicin-insensitive) fibers (secondary hyperalgesia, - Fig. 2). Interestingly, this secondary hyperplasia involves exclusively mechanical stimuli, while thermal sensitivity remains unaltered. This mechanical hypersensitivity is not based on the sensitization of peripheral nerve fibers, but rather is the result of altered central processing of sensory signals. Thus this secondary hyperplasia resembles heterosynaptic plasticity: intense stimulation of nociceptive $C$ fibers leads to the sensitization of the body to signals from other unconditioned fibers. Detailed analysis has shown that, at least in part, these fibers are lowthreshold mechanosensitive fibers, i.e., not nociceptors. Sensitization to signals from these fibers leads to the painful perception of normally painless, mild tactile stimuli, called allodynia. Neurophysiologically, this phenomenon is explained by the fact that signals from non-nociceptive fibers lead to the excitation of pain-signaling neurons. This unphysiological excitation of normally nocispecific projection neurons could be the result of generally increased projection neuron excitability. Alternatively, secondary hyperalgesia and allodynia could also be the result of reduced inhibitory control in the dorsal horn. A popular model to explain allodynia assumes the existence of two normally separate pathways for the spinal transmission of nociceptive and non-nociceptive stimuli. While nocispecific neurons are excited exclusively by nociceptive fibers (marked with “N" in • Fig. 2), so-called wide dynamic range (WDR) neurons are excited by both nociceptive and non-nociceptive fibers. GABAergic and glycinergic neurons keep both pathways functionally separate in vivo. A critical role of this kind played by inhibitory interneurons in the superficial dorsal horn was already proposed more than 45 years in the"gate control" theory of pain [18] (• Fig. 2a). Indeed, inhibitory $\gamma$-aminobutyric acidreleasing (GABAergic) and glycinergic neurons are densely packed in the superficial dorsal horn (• Fig. 2b). Both neu- 
rotransmitters inhibit the excitability of spinal neurons by opening chloride channels (- Fig. 2c). In vivo pharmacological blockade of spinal glycine or $\mathrm{GABA}_{\mathrm{A}}$ receptors leads to symptoms similar to secondary hyperalgesia [27]. On a cellular level reduced inhibition demasks polysynaptic signals from non-nociceptive fibers occurs in previously nocispecific neurons $[3,29]$. These findings show that non-nociceptive fibers are connected with normally nocispecific neurons by excitatory interneurons, and that these connections are masked by inhibitory neurons under physiological conditions. Moreover, GABA and glycine receptor blockade increases the response of lamina I neurons to C-fiber stimulation and induces spontaneous epilepsy-like discharge patterns in these neurons. In the intact organism, such cellular changes lead to corresponding sensory changes. Injecting $\mathrm{GABA}_{\mathrm{A}}$ or glycine receptor blockers induces hypersensitivity to noxious stimuli (hyperalgesia), nociceptive reactions following stimulation of non-nociceptive fibers (allodynia), and behavioral changes suggestive of spontaneous pain. Reducing GABAergic or glycinergic inhibition thus recapitulates important characteristics of pathological pain.

\section{Endogenous mechanisms of disinhibition}

Investigations carried out in recent years by various groups have shown that loss of spinal inhibitory control subsequent to peripheral inflammation, or neuropathies, or following intensive stimulation of nociceptors manifests itself endogenously.

\section{Disinhibition in inflammation}

In the context of inflammatory reactions, increased production of pronociceptive prostaglandins, in particular of prostaglandin $\mathrm{E}_{2}\left(\mathrm{PGE}_{2}\right)$, is seen in peripheral inflamed tissue, but also in the CNS. Induction of cyclooxygenase-2 (COX2), a key enzyme in prostaglandin synthesis, is a key process. On a cellular level, $\mathrm{PGE}_{2}$ production results in facilitated transmission of signals from sensory afferents to second order neurons in the superficial dorsal [20], in direct depo- larization of neurons in the deep dorsal horn [2], as well as in specific inhibition of glycine receptors in the superficial layers of the dorsal horn, i.e., in the central nociceptive innervation territories [34] (- Fig. 3). $\mathrm{PGE}_{2}$ produced in the spinal cord activates $\mathrm{PGE}_{2}$ receptors of the $\mathrm{EP}_{2}$ subtype, leading to increased production of cAMP as well as protein kinase A stimulation [1]. This activation leads in turn to phosphorylation and inhibition of a particular isoform of glycine receptors containing the $\alpha_{3}$ subunit (GlyRa 3 receptors) [9]. The contribution of this process to pain sensitization in the context of various pathologies has been investigated with the help of genetically manipulated mice lacking individual elements of this transduction cascade. $\mathrm{EP}_{2}$ receptor- and GlyRa3deficient mice demonstrated an almost complete absence of nociceptive sensitization following spinal $\mathrm{PGE}_{2}$ injection. Moreover, they recover far more rapidly from inflammation-induced pain sensitization than wild-type mice $[1,9,33]$. Further findings support the relevance of this prostaglandin-mediated disinhibition in inflammation-induced pain sensitization. Thus, mice lacking the catalytic subunit of neuronal protein kinase A also showed decreased pain sensitization by spinally injected $\mathrm{PGE}_{2}$ [16]. Conditional COX-2deficient mice lacking COX-2 specifically in the nervous system did not develop mechanical pain sensitization following peripheral inflammation [31]. Interestingly, EP2- and GlyRa3-deficient mice showed no changes in pain reactions in a series of other pain models. In particular, pain sensitization remained unchanged following peripheral nerve injury and chemical stimulation of nociceptors using capsaicin or formalin $[10,12]$.

\section{Disinhibition following nociceptor stimulation}

Loss of inhibitory spinal pain control also plays an important role in neuropathic pain and in pure activity-related forms of pain sensitization. As discussed above, intense stimulation of nociceptors causes not only nociceptive sensitization at the site of stimulation (primary hyperalgesia), but also in surrounding non-stimulated areas (secondary hyperalgesia, [19]).
e-Neuroforum 2011 · 2:35-41

DOI 10.1007/s13295-011-0018-1

○) Springer-Verlag 2011

H.U. Zeilhofer

Spinal neuroplasticity in chronic pain

\section{Abstract}

Neuroplastic changes play an important role in the generation and maintenance of chronic pain syndromes. Such changes occur at all levels of the neuraxis, from the peripheral terminals of primary sensory neurons to the cerebral cortex. Changes observed in the spinal dorsal horn in particular provide a mechanistic basis for many of the characteristics of chronic pain syndromes. While facilitated synaptic transmission between nociceptive fibers and spinal projection neurons contributes to enhanced perception of noxious stimuli (hyperalgesia), diminished function of GABAergic and glycinergic interneurons not only induces hyperalgesia, but also triggers nociceptive reactions on exposure to innocuous stimuli and spontaneous pain behavior in the absence of any sensory stimulation. Spinal disinhibition thus recapitulates typical symptoms of chronic pathological pain syndromes. Studies performed by various groups over the last 10 years demonstrate that such spinal disinhibition occurs naturally in response to peripheral inflammation and nerve damage. The present article summarizes current status of this research.

\section{Keywords}

Spinal cord · Pain · GABA · Glycine . Somatosensory processing 


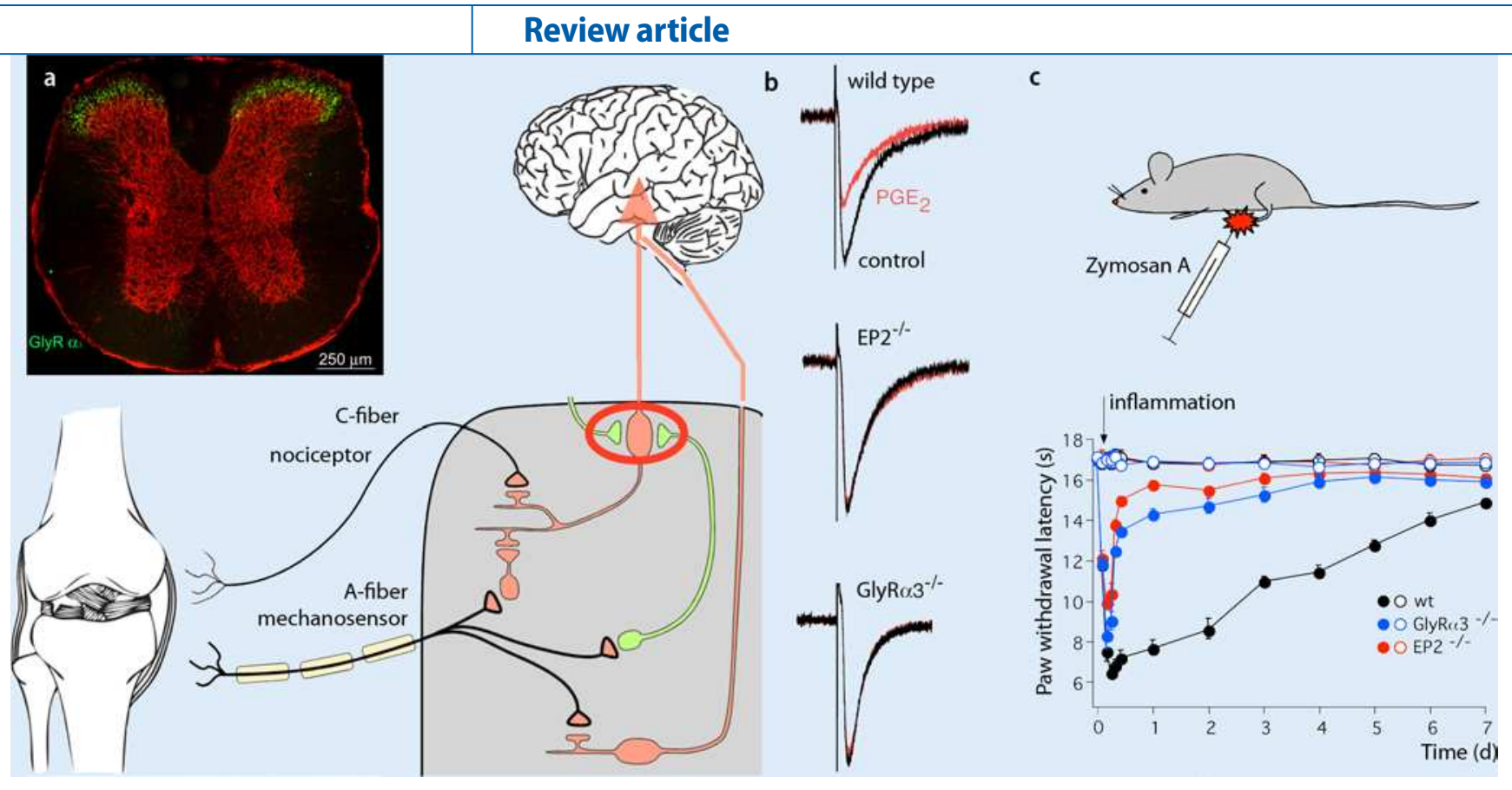

Fig. $3 \Delta$ Spinal disinhibition as a result of peripheral inflammation. a Strychnine-sensitive (inhibitory) glycine receptors are abundant in the dorsal horn. Those containing the a3 subunit are specifically concentrated in the superficial layers where nociceptor endings also lie. Activation of EP2 receptors by $\mathrm{PGE}_{2}$ inhibits this glycine receptor subtype specifically via protein kinase A-dependent phosphorylation. $\mathbf{b}$ In mice lacking the EP2 receptor or Glya3 subunit, no reduction in glycinergic inhibition by $\mathrm{PGE}_{2}$ takes place. $\mathbf{c}$ These mice recover much faster from inflammatory hyperalgesia than wild-type mice. (a,b Modified according to [9]; c modified according to [33])

If one assumes that this activity- and $\mathrm{C}$ fiber-dependent form of secondary hyperalgesia also depends on disinhibition, intense spinal glutamate release from nociceptors should result in reduced synaptic inhibition by glycine or GABA. Heterosynaptic plasticity of this kind requires the existence of a diffusible messenger that transmits the information from nociceptive excitatory synapses to inhibitory synapses. Endocannabinoids and $\mathrm{CB} 1$ cannabinoid receptors couple intense glutamatergic excitation to diminished inhibition in numerous CNS regions [5]. The activation of $\mathrm{CB} 1$ receptors leads to reduced glycine and GABA release also in the dorsal horn of the spinal cord (• Fig. 4). Mice lacking $\mathrm{CB} 1$ receptors, either globally or specifically from inhibitory dorsal horn neurons, are largely protected from capsaicin-induced mechanical pain sensitization [25]. Spinally injected $\mathrm{CB}_{1}$ receptor antagonists or group I metabotropic glutamate receptor antagonists can reverse secondary hyperalgesia in animal models. The pronociceptive effect of endocannabinoids produced in the spinal cord appears surprising at first glance given the many reports on the analgesic action of cannabinoids. However, it must be borne in mind that the reduced pain sensitivity in $\mathrm{CB}$ 1 receptor-deficient mice and the analgesic action of $\mathrm{CB} 1$ receptor antagonists is limited to activity-dependent pain sensitization and has not been observed in inflammatory or neuropathic pain models. This is supported by findings from acute human pain models [ $[15$, 22], as well as from clinical studies in postoperative pain patients. In these settings, cannabinoids not only failed to show an analgesic effect, but instead resulted in increased pain. The fact that $\mathrm{CB} 1$ receptor agonists relieve pain in chronic pain patients could therefore mean that purely activity-dependent mechanisms of secondary hyperalgesia play only a minor role in chronic pain.

\section{Disinhibition following peripheral nerve injury}

A third form of pathological pain sensitization occurs following damage to the peripheral or central nervous system. In an experimental setting, neuropathic pain is usually evoked through mechanical lesion (ligature or partial transsection) of the sciatic nerve. This elicits sensitization of the affected extremity to thermal and mechanical stimuli, persisting over several weeks. In recent years, it has been observed that microglial cells play a crucial role in neuropathic pain sensitization (- Fig. 5). Following peripheral nerve lesion, these cells are recruited in a multistage process in the spinal innervation area of the injured nerve fibers. After neuronal damage, primary sensory fibers release the cytokine CCL2 (also known as macrophage chemoattractant protein-1, MCP-1), which binds to $\mathrm{CCR}_{2}$ receptors on microglial cells $[28,36]$. Further microglial activation depends on purinergic signals, which arise from increased expression of ionotropic $\mathrm{P}_{2} \mathrm{X}_{4}$ receptors on microglial cells. In order to cause pain sensitization, microglial activation must lead ultimately to altered neuronal communication. This task is fulfilled by brainderived neurotrophic factor (BDNF), the production and release of which is triggered by activation of $\mathrm{P}_{2} \mathrm{X}_{4}$ receptors, microglial calcium signals and subsequent activation of the p38 MAP kinase signaling pathway [8]. BDNF binds to neuronal trk-B receptors and leads to increased expression of the potassium-chloride exporter $\mathrm{KCC}_{2}$ [7]. $\mathrm{KCC}_{2}$ keeps the intracellular chloride concentration in neu- 
Fig. 4 Activation of cannabinoid $C B 1$ receptors by the cannabinoid receptor agonists WIN 55,212-2 $(W I N)$ results in reduced release of GABA and glycine, while glutamate release from excitatory spinal interneurons remains unaltered. Inhibition of GABA and glycine release by WIN 55,212 2 is reversed by the CB1 receptor antagonist AM251. Intense glutamate release from nociceptors induces the production and release of endocannabinoids and could thus link intense nociceptor stimulation to reduced synaptic inhibition. Endocannabinoids and CB1 receptors are thus able to function as mediators of secondary C fiber-transmitted hyperalgesia. (Modified according to [25])

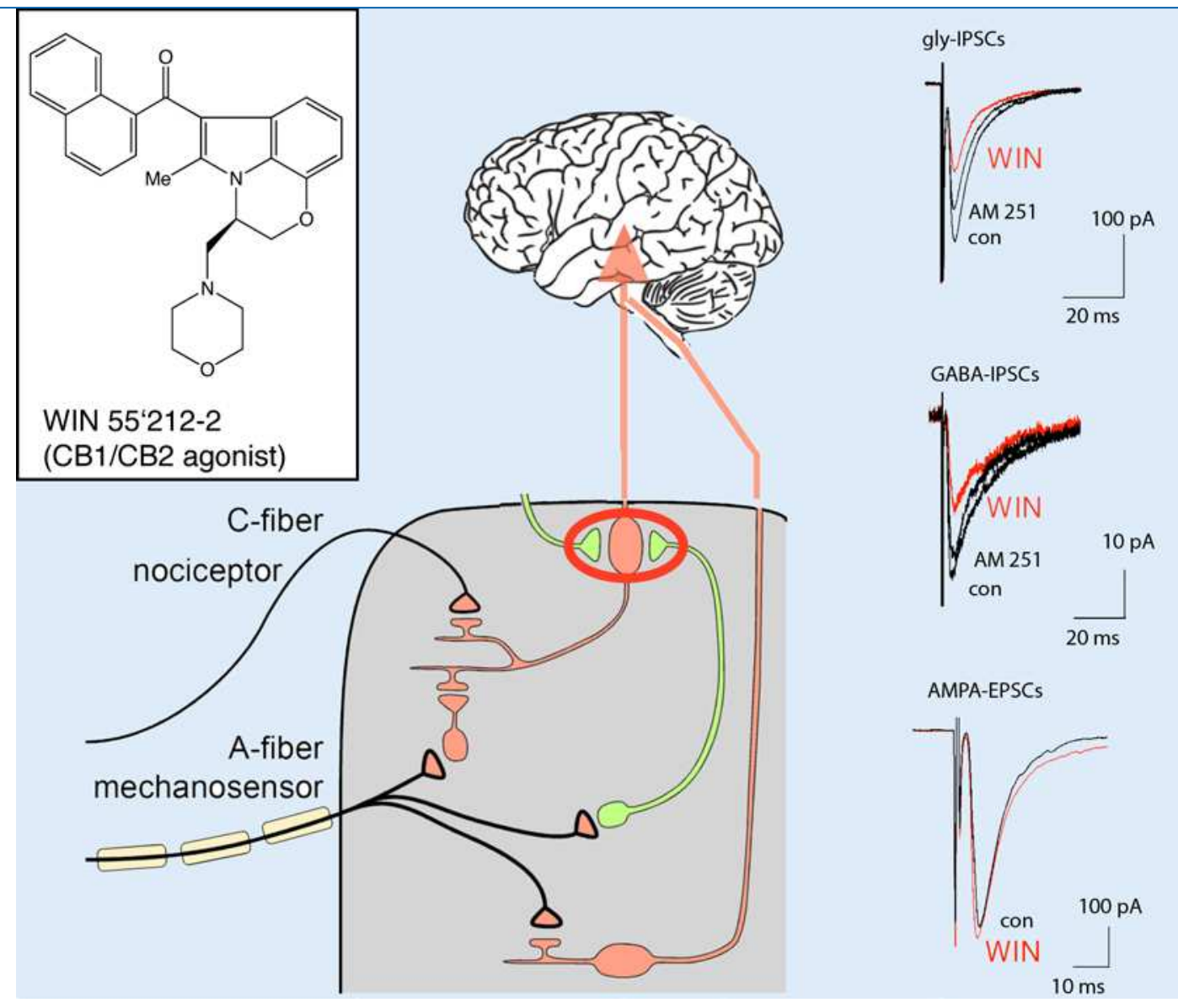

rons low, thus enabling the hyperpolarizing action of GABA and glycine. Conversely, reduced $\mathrm{KCC}_{2}$ expression results in an increase in the intracellular chloride concentration and reduced inhibition by GABA and glycine. In extreme cases, GABAergic and glycinergic inhibition can even be reversed into depolarization and excitation. Neurons in the superficial dorsal horn, which have only a relatively low chloride extrusion capacity, appear to be most susceptible to these changes [6]. The question of whether GABA indeed acquires an excitatory effect or whether its inhibitory action is merely reduced is important for possible therapeutic implications. The majority of publications report that a local increase in GABAergic transmission mitigates neuropathic pain $[14,35]$. It is difficult to reconcile this finding with an excitatory effect of GABA, suggesting rather that the inhibitory action of GABA and glycine is reduced but not changed into one of excitation. Alternatively, the analgesic effect of enhanced GABAergic transmission may

result from an increase in shunting conductance.

\section{Implications for the treatment of chronic pain}

The findings discussed above demonstrate that pain pathologies of varying origin converge on a reduction of inhibitory pain control in the spinal cord. Pharmacologically increased GABAergic and glycinergic inhibition in the dorsal horn may therefore represent a new rational approach to the treatment of chronic pain, which should be equally effective irrespective of the contribution of inflammatory or neuropathic components. Indeed, increased synaptic inhibition by $\mathrm{GABA}_{\mathrm{A}}$ receptor modulators has a marked antihyperalgesic effect in inflammatory and neuropathic pain sensitization [35]. Investigations in $\mathrm{GABA}_{\mathrm{A}}$ receptor mutant mice show that these desired spinal effects are based on the activation of specific $\mathrm{GABA}_{\mathrm{A}}$ receptor subtypes containing the $\alpha_{2}$ and/ or $\alpha_{3}$ subunit [14]. This specificity could prove crucial for the development of new pharmaceuticals, since the typical undesired effects of classic benzodiazepines (sedation, cognitive dysfunction, and addiction) require $\alpha_{1}-\mathrm{GABA}_{\mathrm{A}}$ receptor activation. At least in animal models, subtype-selective activators of $\mathrm{GABA}_{\mathrm{A}}$ receptors have shown the desired antihyperanalgesic action, while undesired effects have been hitherto less pronounced [35].

In this context, increasing glycinergic inhibition pharmacologically could also prove to be very interesting. Currently, there are no compounds available which would do for glycine receptors what benzodiazepines do for $\mathrm{GABA}_{\mathrm{A}}$ receptors. However, glycine receptors still carry binding sites for allosteric modulators such as various cannabinoids [11]. Recent results even suggest that at least part of the analgesic action of cannabis (tetrahydrocannabinol, THC) is based on direct interaction with spinal glycine receptors [32].

\section{A model of neuronal connectivity}

A mechanistic understanding of the development of secondary hyperalgesia and 


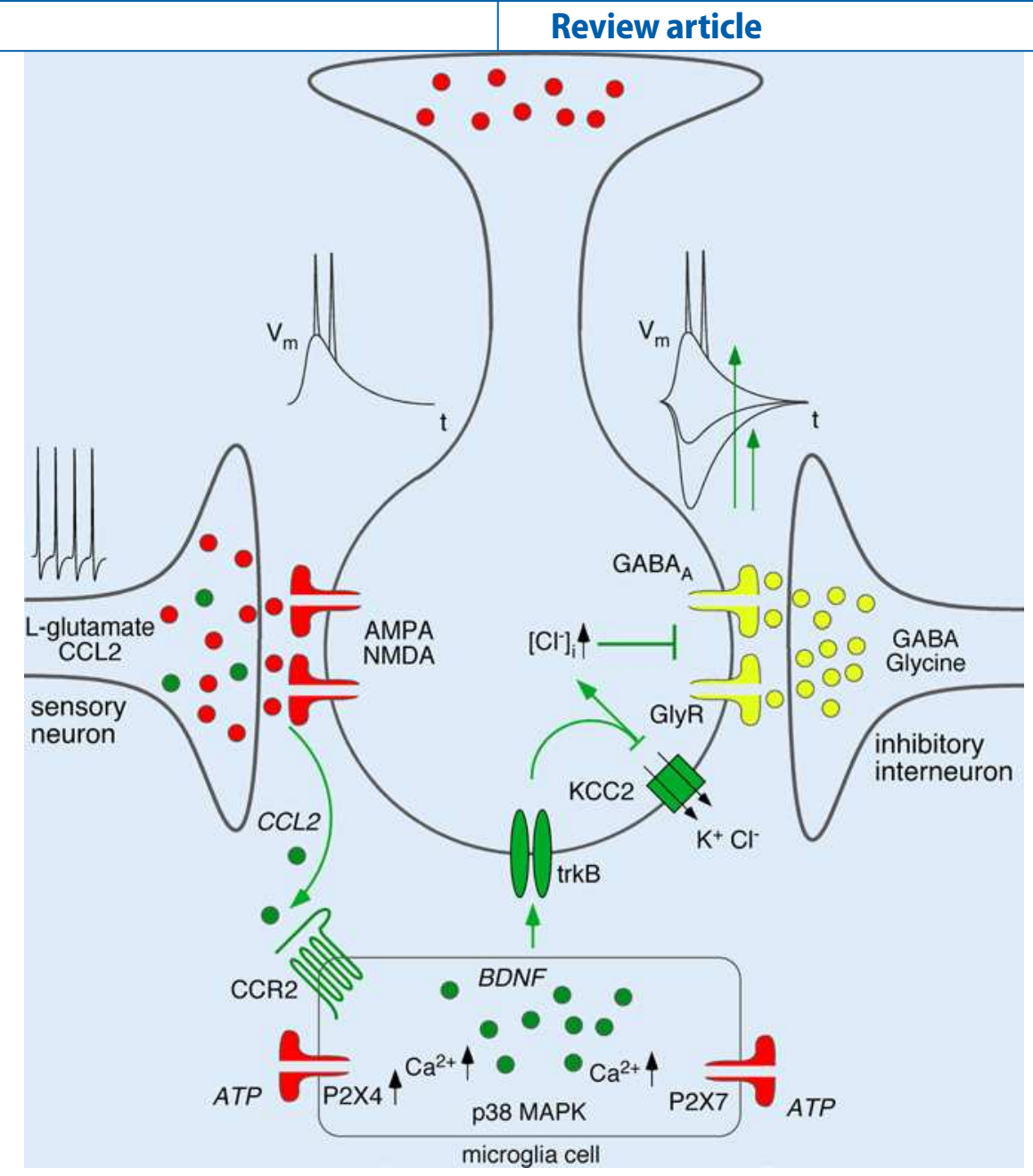

Fig. $5 \Delta$ The role of microglia in the development of hyperalgesia following peripheral nerve lesion. A central neuron is shown (middle) in the superficial dorsal horn, which receives synaptic signals from a damaged sensory fiber (left) and an inhibitory interneuron (right). Microglial cells (bottom) represent the functional connection between damaged nerve fibers and reduced synaptic inhibition. Following peripheral nerve lesion, the chemokine CCL2 is released from the endings of sensory nerve fibers. CCL2 recruits spinal microglia via activation of CCR2 receptors, additionally leading to increased expression of purinergic $\mathrm{P} 2 \mathrm{X} 2$ receptors. Stimulation of the latter by ATP in turn induces the production and release of BDNF via a 338 MAP kinase-dependent process. BDNF then binds to trkB receptors on neurons in the dorsal horn, leading to reduced expression of the chloride exporter $\mathrm{KCC} 2$, which ultimately results in an increase in the intracellular chloride concentration and attenuated GABAergic and glycinergic inhibition. In this way, BDNF connects microglial activation with reduced synaptic inhibition in the dorsal horn

allodynia crucially depends on identifying the relevant sensory nerve fibers and spinal (inter-) neurons, as well as on accurate knowledge of their connectivity. Although we are still far from seeing the full picture, interesting observations have been made in sub-fields in recent years. Thus, a hitherto unknown fiber class could be identified which, when activated, leads to abnormal pain sensation in secondary hyperalgesic/allodynic areas. This class represents a subpopulation of non-myelinated, lowthreshold mechanosensitive fibers characterized by the expression of a certain vesicular glutamate transporter $\left(\mathrm{VGluT}_{3}\right)$ and the absence of typical characteristic peptidergic and non-peptidergic nociceptors [4]. The vast majority of these neurons bind neither isolectin $\mathrm{B}_{4}\left(\mathrm{IB}_{4}\right)$ nor antibodies to calcitonin gene-related peptide (CGRP), two classical markers of primary nociceptors. VGluT3-deficient mice showed markedly reduced secondary hyperalgesia following subcutaneous capsaicin injection, as well as reduced mechanical sensitization in the presence of inflammation, peripheral nerve lesion, or following cutaneous injury. These fibers terminate in the spinal cord in the lamina I and at the border between lamina II and III, in the immediate vicinity of protein kinase $\mathrm{C} \gamma(\mathrm{PKC} \gamma)$-expressing neurons. These neurons are excitatory interneurons situated at the border between innervation regions of nociceptive and non-nociceptive fibers $[23,26]$. Remarkably, $\mathrm{PKC} \gamma$ deficient mice demonstrated strongly reduced hyperalgesia following peripheral nerve lesion and inflammation [17]. Moreover, blockade of PKC $\gamma$ also prevents glycine receptor blockade-induced mechanical hyperalgesia. Experiments in which neuronal activation was demonstrated by $c$-fos expression also showed that $\mathrm{PKC} \gamma$ positive neurons are activated by non-nociceptive but not by nociceptive fibers. Although not unequivocally proven to date, it is likely that $\mathrm{PKC} \gamma$-positive neurons project via polysynaptic connections to normally nocispecific neurons. Interneurons with dendritic trees extending in a stellate formation (stellate cells) in the superficial posterior horn are possibly interconnected between VGlut3-positive fibers and $\mathrm{PKC} \gamma$-positive neurons. The nature of the inhibitory neurons controlling this circuit is even less well understood. Functional neurobiological methods developed recently, such as targeted stimulation of defined neuronal populations by light-activated ion channels (channel rhodopsins) or their targeted destruction using cell-specific toxins, promise to provide new insights into this exciting field of research.

\section{Corresponding address \\ Prof. Dr. H.U.Zeilhofer}

Institut für Pharmakologie und Toxikologie,

Universität Zürich

Winterthurerstrasse 190, 8057 Zürich

Schweiz

zeilhofer@pharma.uzh.ch

H.U. Zeilhofer Born 1963; studied medicine at the University of Erlangen-Nuremberg and Harvard Medical School. Doctorate (1991) and habilitation in pharmacology and toxicology (1997) at the Institute for Experimental and Clinical Pharmacology and Toxicology at the University of Erlangen-Nuremberg. Since 2005, Professor of Pharmacology at the University of Zurich and the ETH Zurich.

Acknowledgements. The author's work on the spinal control of nociception is currently funded by the Swiss National Science Foundation, the German Research Foundation, as well as by a European Research Council (ERC) Advanced Investigator Grant. 


\section{References}

1. Ahmadi S, Lippross S, Neuhuber WL, Zeilhofer HU (2002) PGE $E_{2}$ selectively blocks inhibitory glycinergic neurotransmission onto rat superficial dorsal horn neurons. Nat Neurosci 5:34-40

2. Baba H, Ji RR, Kohno T, Moore KA, Ataka T, Wakai A, Okamoto M, Woolf CJ (2003) Removal of GABAergic inhibition facilitates polysynaptic $A$ fiber-mediated excitatory transmission to the superficial spinal dorsal horn. Mol Cell Neurosci 24:818-830

3. Baba H, Kohno T, Moore KA, Woolf CJ (2001) Direct activation of rat spinal dorsal horn neurons by prostaglandin E2. J Neurosci 21:1750-1756

4. Cavanaugh DJ, Lee H, Lo L, Shields SD, Zylka MJ, Basbaum Al, Anderson DJ (2009) Distinct subsets of unmyelinated primary sensory fibers mediate behavioral responses to noxious thermal and mechanical stimuli. Proc Natl Acad Sci U S A 106:9075-9080

5. Chevaleyre V, Takahashi KA, Castillo PE (2006) Endocannabinoid-mediated synaptic plasticity in the CNS. Annu Rev Neurosci 29:37-76

6. Cordero-Erausquin M, Coull JA, Boudreau D, Rolland M, De Koninck Y (2005) Differential maturation of GABA action and anion reversal potential in spinal lamina I neurons: impact of chloride extrusion capacity. J Neurosci 25:9613-9623

7. Coull JA, Beggs S, Boudreau D, Boivin D, Tsuda M, Inoue K, Gravel C, Salter MW, De Koninck Y (2005) BDNF from microglia causes the shift in neuronal anion gradient underlying neuropathic pain. $\mathrm{Na}$ ture 438:1017--1021

8. Coull JA, Boudreau D, Bachand K, Prescott SA, Nault F, Sik A, De Koninck P, De Koninck Y (2003) Trans-synaptic shift in anion gradient in spinal lamina I neurons as a mechanism of neuropathic pain. Nature 424:938-942

9. Harvey RJ, Depner UB, Wässle H, Ahmadi S, Heindl C, Reinold H, Smart TG, Harvey K, Schütz B, AboSalem OM, Zimmer A, Poisbeau P, Welzl H, Wolfer DP, Betz H, Zeilhofer HU, Müller U (2004) GlyRa3: an essential target for spinal PGE2-mediated inflammatory pain sensitization. Science 304:884887

10. Harvey VL, Caley A, Müller UC, Harvey RJ, Dickenson $A H$ (2009) A selective role for a3 subunit glycine receptors in inflammatory pain. Front $\mathrm{Mol}$ Neurosci 2:14

11. Hejazi N, Zhou C, Oz M, Sun H, Ye JH, Zhang L (2006) Delta9-tetrahydrocannabinol and endogenous cannabinoid anandamide directly potentiate the function of glycine receptors. Mol Pharmacol 69:991-997

12. Hösl K, Reinold H, Harvey RJ, Müller U, Narumiya S, Zeilhofer HU (2006) Spinal prostaglandin E receptors of the EP2 subtype and the glycine receptor a3 subunit, which mediate central inflammatory hyperalgesia, do not contribute to pain after peripheral nerve injury or formalin injection. Pain 126:46-53

13. Ikeda H, Stark J, Fischer H, Wagner M, Drdla R, Jager T, Sandkuhler J (2006) Synaptic amplifier of inflammatory pain in the spinal dorsal horn. Science 312:1659-1662

14. Knabl J, Witschi R, Hösl K, Reinold H, Zeilhofer UB, Ahmadi S, Brockhaus J, Sergejeva M, Hess A, Brune K, Fritschy J-M, Rudolph U, Möhler H, Zeilhofer HU (2008) Reversal of pathological pain through specific spinal $G A B A_{A}$ receptor subtypes. Nature 451:330-334
15. Kraft B, Frickey NA, Kaufmann RM, Reif M, Frey R, Gustorff B, Kress HG (2008) Lack of analgesia by oral standardized cannabis extract on acute inflammatory pain and hyperalgesia in volunteers. Anesthesiology 109:101-110

16. Malmberg AB, Brandon EP, Idzerda RL, Liu H, McKnight GS, Basbaum AI (1997a) Diminished inflammation and nociceptive pain with preservation of neuropathic pain in mice with a targeted mutation of the type I regulatory subunit of CAMP-dependent protein kinase. J Neurosci 17:7462-7470

17. Malmberg AB, Chen C, Tonegawa S, Basbaum Al (1997b) Preserved acute pain and reduced neuropathic pain in mice lacking PKC . Science 278:279283

18. Melzack R, Wall PD (1965) Pain mechanisms: a new theory. Science 150:971-979

19. Meyer R, Ringkamp M, Campbell J, Raja S (2006) Peripheral mechanisms of cutaneous nociception. In: McMahon SB, Koltzenburg M (eds) Textbook of pain. Churchill Livingstone/Elsevier, pp 3-34

20. Minami T, Okuda-Ashitaka E, Hori Y, Sakuma S, Sugimoto T, Sakimura K, Mishina M, Ito S (1999) Involvement of primary afferent $\mathrm{C}$-fibres in touchevoked pain (allodynia) induced by prostaglandin E2. Eur J Neurosci 11:1849-1856

21. Miraucourt LS, Dallel R, Voisin DL (2007) Glycine inhibitory dysfunction turns touch into pain through PKC $\gamma$ interneurons. PLoS ONE 2:e1116

22. Naef $M$, Curatolo $M$, Petersen-Felix S, ArendtNielsen L, Zbinden A, Brenneisen R (2003) The analgesic effect of oral delta-9-tetrahydrocannabinol (THC), morphine, and a THC-morphine combination in healthy subjects under experimental pain conditions. Pain 105:79-88

23. Neumann S, Braz JM, Skinner K, Llewellyn-Smith IJ, Basbaum AI (2008) Innocuous, not noxious, input activates PKC $\gamma$ interneurons of the spinal dorsal horn via myelinated afferent fibers. J Neurosci 28:7936-7944

24. Nichols ML, Allen BJ, Rogers SD, Ghilardi JR, Honore P, Luger NM, Finke MP, Li J, Lappi DA, Simone DA, Mantyh PW (1999) Transmission of chronic nociception by spinal neurons expressing the substance $P$ receptor. Science 286:1558-1561

25. Pernia-Andrade AJ, Kato A, Witschi R, Nyilas R, Katona I, Freund TF, Watanabe M, Filitz J, Koppert W, Schüttler J, Ji G, Neugebauer V, Marsicano G, Lutz B, Vanegas H, Zeilhofer HU (2009) Spinal endocannabinoids and CB1 receptors mediate $C$-fiber-induced heterosynaptic pain sensitization. Science 325:760-764

26. Polgar E, Fowler JH, McGill MM, Todd AJ (1999) The types of neuron which contain protein kinase $C \gamma$ in rat spinal cord. Brain Res 833:71-80

27. Sivilotti L, Woolf CJ (1994) The contribution of $\mathrm{GABA}_{A}$ and glycine receptors to central sensitization: disinhibition and touch-evoked allodynia in the spinal cord. J Neurophysiol 72:169-179

28. Thacker MA, Clark AK, Bishop T, Grist J, Yip PK, Moon LD, Thompson SW, Marchand F, McMahon SB (2009) CCL2 is a key mediator of microglia activation in neuropathic pain states. Eur J Pain 13:263-272

29. Torsney C, MacDermott AB (2006) Disinhibition opens the gate to pathological pain signaling in superficial neurokinin 1 receptor-expressing neurons in rat spinal cord. J Neurosci 26:1833-1843

30. Tsuda M, Shigemoto-Mogami Y, Koizumi S, Mizokoshi A, Kohsaka S, Salter MW, Inoue K (2003) P2X4 receptors induced in spinal microglia gate tactile allodynia after nerve injury. Nature 424:778-783
31. Vardeh $D$, Wang $D$, Costigan $M$, Lazarus $M$, Saper CB, Woolf CJ, Fitzgerald GA, Samad TA (2009) COX2 in CNS neural cells mediates mechanical inflammatory pain hypersensitivity in mice. J Clin Invest 119:287-294

32. Xiong W, Cheng K, Cui T, Godlewski G, Rice KC, Xu $Y$, Zhang L (2011) Cannabinoid potentiation of glycine receptors contributes to cannabis-induced analgesia. Nat Chem Biol 7:296-303

33. Zeilhofer HU (2007) Prostanoids in nociception and pain. Biochem Pharmacol 73:165-174

34. Zeilhofer HU (2005) The glycinergic control of spinal pain processing. Cell Mol Life Sci 62:2027-2035

35. Zeilhofer HU, Möhler H, Di Lio A (2009) GABAergic analgesia: new insights from mutant mice and subtype-selective agonists. Trends Pharmacol Sci 30:397-402

36. Zhang J, De Koninck Y (2006) Spatial and temporal relationship between monocyte chemoattractant protein-1 expression and spinal glial activation following peripheral nerve injury. J Neurochem 97:772-783 